\title{
Effect of dexpanthenol on colonic anastomosis healing in rats"
}

\author{
CELAL SAHIN ERMUTLU, EKIN EMRE ERKILIC*, ENGIN KILIC, ALI HAYDAR KIRMIZIGUL*, \\ SERPIL DAG**, METIN OGUN ${ }^{* * *}$, VEDAT BARAN, OGUZ MERHAN ${ }^{* * *}$
}

\begin{abstract}
Department of Surgery, *Department of Internal Medicine, ${ }^{* *}$ Department of Pathology, ***Department of Biochemistry, Faculty of Veterinary Medicine, Kafkas University, Kars, Turkey
\end{abstract}

\section{Ermutlu C. S., Erkilic E. E., Kilic E., Kirmizigul A. H., Dag S., Ogun M., Baran V., Merhan O. Effect of dexpanthenol on colonic anastomosis healing in rats \\ Summary}

The purpose of this study was to perform the clinical, histopathologic and biochemical evaluation of the effects of intraperitoneally (IP) administered dexpanthenol (dxp) on colonic anastomosis healing in rats. The study was conducted on a total of 28 rats divided into four groups comprising seven rats each. Group I was designated as the control group, group II as the dxp group, group III as the anastomosis group, and group IV as the anastomosis + dxp group. The groups were compared in terms of intestinal bursting pressure, adhesion formation, nitric oxide (NO) and malondialdehyde (MDA) levels, total antioxidant capacity (TAC) and total oxidant capacity (TOC) in blood and intestinal homogenates, as well as histopathologic findings. Dxp decreased adhesion formation (6 rats in group III and 4 rats in group IV). Mean bursting pressures were higher in the dxp groups than in the other groups (group II $=\mathbf{2 5 4 . 3} \pm \mathbf{4 2 . 1} \mathrm{mmHg}$, group IV $=109.3 \pm 34.5 \mathrm{mmHg}$ ). Moreover, there was a remarkable decrease in the levels of NO and MDA and in blood oxidative stress parameters in the dxp groups. The results suggest that dxp increased intestinal bursting pressure by accelerating healing in the anastomosis line and decreased adhesion formation, positively affecting healing. Dexpanthenol, which was found to have positive effects in the experimental rat model, can be introduced into clinical practice.

Keywords: rat, colonic anastomosis, dexpanthenol

Colonic anastomoses make up an important proportion $(30 \%)$ of gastrointestinal system surgeries $(9,26)$, and anastomotic leakages following procedures that require colon resection are of significant importance. Anastomotic leakage has also been reported among the main reasons for postoperative mortality and morbidity (12). Fistula formation, bleeding and anastomotic stenosis are among other complications that develop after colonic anastomoses. Preventing leakage in the anastomotic line, decreasing tension and maintaining blood supply to the affected area are important, and many suturing techniques have been developed for this purpose (15). Various anastomosis methods can be used to prevent anastomotic leakage, and various measures, such as antibiotic prophylaxis, fasting before surgery and bowel preparation by enema or purgatives, should become a rule. The purpose of colonic anastomosis is to promote recovery without complications in the shortest

1) This study was supported by Kafkas University, Scientific Research Project Commission (Project No. 2017-TS-49) and presented as an oral presentation at V. International Multidisciplinary Congress of Eurasia, Barcelona, Spain, July 24-26, 2018. possible time without causing stenosis in the bowel lumen or intestinal leakage $(4,9,26)$. Suturing/stapling and suture-free techniques have been attempted for this purpose. However, these techniques have not yielded a perfect result. Several suture-free methods have been developed as an alternative to suturing methods, but various complications, mainly anastomotic stenosis, have been reported for them $(3,4,8,14,16)$.

The main causes of the complications of colonic anastomoses are prolonged immobilisation of the colon while preparing for anastomosis, overuse of cauterisation to achieve haemostasis, prolonged and very tight gripping with haemostatic forceps, as well as tight suturing and stapling causing damage and ischaemia in vascular tissues $(4,8)$.

In addition to synthetic and organic meshes (4), absorbable surgical barrier films (8) and prebiotics such as kephir (9), procedures such as omentoplasty (16) have been attempted to prevent leakage after colonic anastomosis.

Dexpanthenol is an antioxidant agent, and it is converted to pantothenic acid when administered orally or 
parenterally. Because of the presence of pantothenic acid (vitamin B5) in its structure, dexpanthenol is more often used topically or as injection in cosmetic fields and wound healing (19-21, 24). Pantothenic acid plays a role in cellular energy generation as well as in the adrenal and cardiovascular systems and in the synthesis of vitamins, amino acids, fatty acids, cholesterol and steroid hormones. In addition to these characteristics, it contributes to wound healing, particularly because of its epithelizing effect. Considering these positive effects, dexpanthenol might have positive effects on intestinal anastomotic healing.

Based on this assumption, the present study aimed to evaluate the clinical, histopathologic and biochemical effects of dexpanthenol on anastomotic healing when administered IP for 5 days following anastomosis performed after total colonic enterotomy in rats.

\section{Material and methods}

The study was started as previously planned following approval of the Kafkas University Local Ethics Committee for Animal Experiments (KAUHADYEK-2017-026).

Animals. The study included twenty-eight adult rats (Rattus norvegicus) with an average weight of $338 \mathrm{~g}$ (range: 306-361 g), obtained from the Kafkas University Experimental Animals Research Centre. The rats were fed ad libitum with standard rat pellet feed and water until study completion. Environmental adaptation was provided for 1 week before the experiment. During the adaptation period and the experiment, the rats were kept in a $12-\mathrm{h} / 12$-h light/ dark cycle at $20-22^{\circ} \mathrm{C}$ and a $45-55 \%$ humidity. Four groups were created comprising seven rats each. Group I (control group) rats were kept in the same environment with the other rats. No operations were performed on rats in this group, but blood and other tissue samples were evaluated to set reference values. Group II rats were administered dexpanthenol (500 $\mathrm{mg} / \mathrm{kg} / \mathrm{IP}$ ) every $24 \mathrm{~h}$ for 5 days. Group III rats received standard surgical care after colonic anastomosis. Dexpanthenol $(500 \mathrm{mg} / \mathrm{kg} / \mathrm{IP})$ was administered to group IV rats every $24 \mathrm{~h}$ for 5 days following colonic anastomosis.

Anaesthesia protocol. Xylazine (10 mg/kg IM; Rompun, Bayer, Germany) and ketamine $\mathrm{HCl}(100 \mathrm{mg} / \mathrm{kg}$ IM, 10\% Ketasol; Richter Pharma, Australia) were preferred anaesthetic agents.
Surgery. After anaesthesia administration, the rats were placed in the dorsal recumbent position. Routine shaving and disinfection were performed at the linea alba. The area was covered with sterile covers, and operations were performed under aseptic conditions. A full-thickness incision was made, reaching the distal colon of all rats to achieve standardisation (Fig. 1a). Anastomosis was created using a first-level, simple continuous suture and second-level Lembert suture method with 5/0 polyglactin 910 (Vicryl, Ethicon, USA) sutures (Fig. 1b, 1c). The abdomen was closed, and postoperative monitoring was performed.

Blood samples were obtained for biochemical evaluation before the study and at postoperative day 5 . Rats in all groups were sacrificed by administering a high dose of sodium pentobarbital (100 mg/kg IM).

Necroscopy. After carefully approaching the abdomen, the presence of adhesions on the anastomosis line and in the surrounding tissues was macroscopically evaluated according to the visual adhesion scale of Jenkins et al (11). It was recorded as $(+)$ if an adhesion was present and as $(-)$ if it was absent (Fig. 2). At the same time, the region was evaluated in terms of anastomotic leakage and the presence of perito-

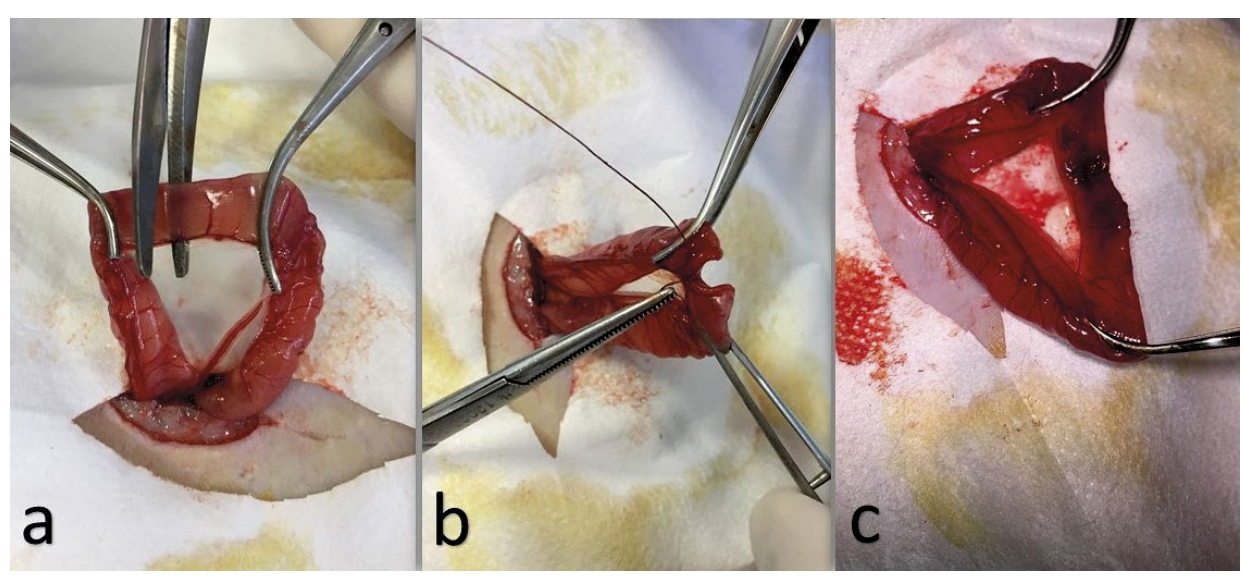

Fig. 1. Application of colonic anastomosis: a. A full-thickness incision of the colon; b. Anastomosis sutures; c. Appearance after completion of anastomosis

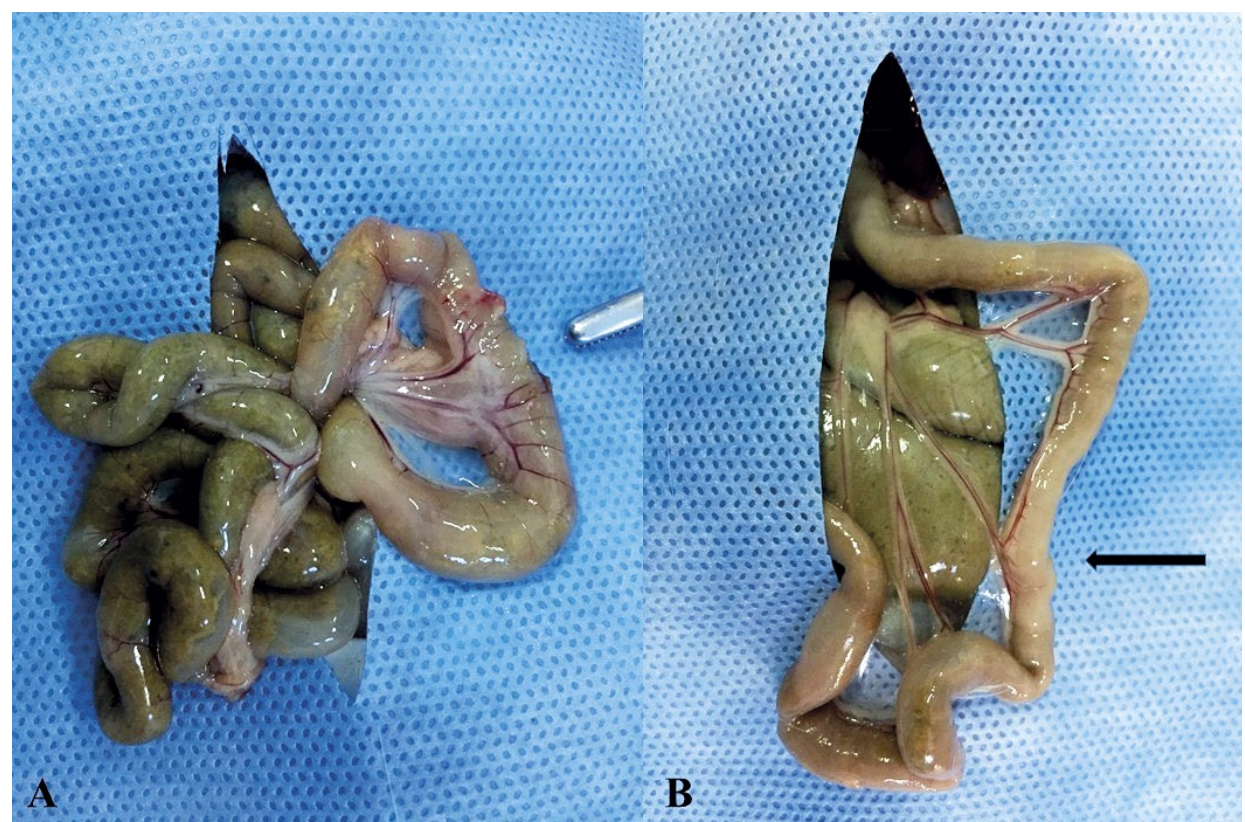

Fig. 2. Macroscopic evaluation of the anastomosis line on day 5 (A. adhesion $(+)$, B. adhesion (-)) 


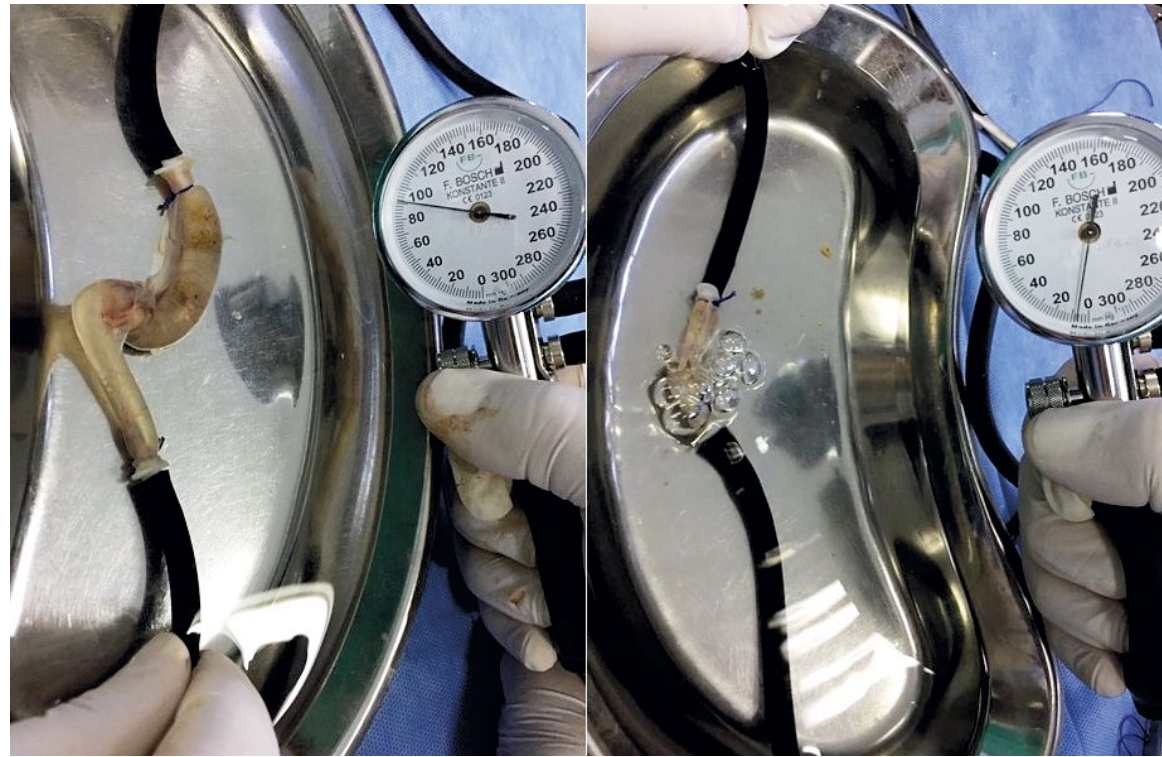

Fig. 3. Measurement of bursting pressure

nitis. A colon segment of adequate length was acquired by excision from the proximal and distal colon to include the anastomosis line. The segment was connected to an air pump and a pressure gauge using a silk suture to prevent leakage and was slowly inflated while submerged in a water tub. The pressure $(\mathrm{mmHg})$ at which air bubbles were observed was recorded as the bursting pressure (Fig. 3).

Histopathology. Tissue samples of the colon including the anastomosis line were placed in formaldehyde solution with $10 \%$ buffer for a histopathologic examination. Five-micron-thick slices cut from paraffin blocks prepared according to routine laboratory procedures were stained with haematoxylin-eosin (HE) to evaluate histopathologic changes in the anastomosis line and with Masson's trichrome to evaluate collagen distribution. The slices were then evaluated under a light microscope, and wound healing was evaluated using the Verhofstad scale $(10,23)$. Sections from each anastomotic line were evaluated in terms of reepithelisation in the mucosa, necrosis, polymorphonuclear leukocyte (PMNL), mononuclear cell infiltration, angiogenesis, fibroblast proliferation and collagen synthesis.

Biochemical evaluation. NO and MDA levels, as well as TAC and TOC, were measured in colon homogenates including the anastomosis line and blood samples taken before the operation and at postoperative day 5. NO and

Tab. 1. Distribution of adhesion grades in groups III and IV $(n=7)$

\begin{tabular}{|l|c|c|}
\hline \multicolumn{1}{|c|}{ Adhesion grades } & Group III & Group IV \\
\hline $\mathbf{0}$ (No adhesion) & 1 & 3 \\
\hline (Adhesion that separated with light blunt dissection) & 2 & 3 \\
\hline (Adhesion that separated with aggressive blunt dissection) & 4 & 1 \\
3 (Adhesion that separated with sharp dissection) & 0 & 0 \\
\hline
\end{tabular}

Tab. 2. Bursting values ( $\mathrm{mmHg}$ ) in the groups (mean value \pm standard error)

\begin{tabular}{|c|c|c|c|c|}
\hline Group I & Group II & Group III & Group IV & p value \\
\hline $232.14 \pm 16.54^{\mathrm{a}}$ & $254.29 \pm 15.90^{\mathrm{a}}$ & $\mathbf{7 8 . 5 7} \pm 12.76^{\mathrm{b}}$ & $109.29 \pm 13.02^{\mathrm{b}}$ & $\mathrm{p}<0.001$ \\
\hline
\end{tabular}

Explanation: $\mathrm{a}, \mathrm{b}$ - means with different superscript letters differ significantly at $\mathrm{p} \leq 0.05$
MDA levels, as well as TAC and TOC, were measured by the colorimetric method with a spectrophotometer $\left(\right.$ Epoch $^{\circledR}$, Biotek, USA). NO levels were measured according to the method reported by Miranda et al. (17); MDA levels were measured according to the method reported by Yoshika et al. (25) TAC and TOC were determined by the automatic colorimetric method developed by Erel $(5,6)$ with commercial kits (Rel Assay Diagnostics, MEGA TIP, Sehitkamil, Gaziantep, Turkey).

Statistics. Data collected from the study were subjected to statistical analysis using SPSS ${ }^{\circledR} 18.0$ software package. After normality testing, the groups were analysed using one-way analysis of variance and the post hoc Tukey's HSD test. The analyses of the variables for each group between day 0 and day 5 were evaluated using the paired T-test. Data obtained were expressed as mean \pm standard deviation. P-values of less than 0.05 were considered statistically significant.

\section{Results and discussion}

Clinical observations. During routine daily care and controls, the rats were monitored in terms of their feeding behaviour and interest in the environment. They showed willingness to eat and defecate from day 1 onwards after recovering from anaesthesia.

Necropsy findings. Rats that were sacrificed at day 5 were first evaluated for the presence of peritoneal adhesions. Adhesion formation was detected in six rats in group III and four rats in group IV (Tab. 1). Intestinal segments including the anastomosis line were evaluated in terms of bursting pressure; the mean bursting pressure was highest in group II $(254.3 \pm 42.1$ $\mathrm{mmHg}$ ). The mean bursting pressure was $232.1 \pm 43.8$ $\mathrm{mmHg}$ in group I, $109.3 \pm 34.5 \mathrm{mmHg}$ in group IV, and $78.6 \pm 33.8 \mathrm{mmHg}$ in group III (Tab. 2). Comparison of the mean intestinal bursting pressures revealed no statistically significant difference between group I and group II. Although groups III and IV showed similar mean bursting pressures, dexpanthenol remarkably increased mean values in all four groups.

Histopathologic findings. The colon had a normal histological appearance in groups I and II (Fig. 4a). As no histopathologic lesions were found in these groups, they were not included for statistical analysis.

The histopathologic examination of HEstained slices showed predominance of fibroblastic activity with angiogenesis and wound healing at the proliferative fibrous repair stage in three rats in group III. In these rats, the predominant inflammatory cell types were lymphocytes and macrophages, and incomplete re-epithelisation was observed on the mucosal 


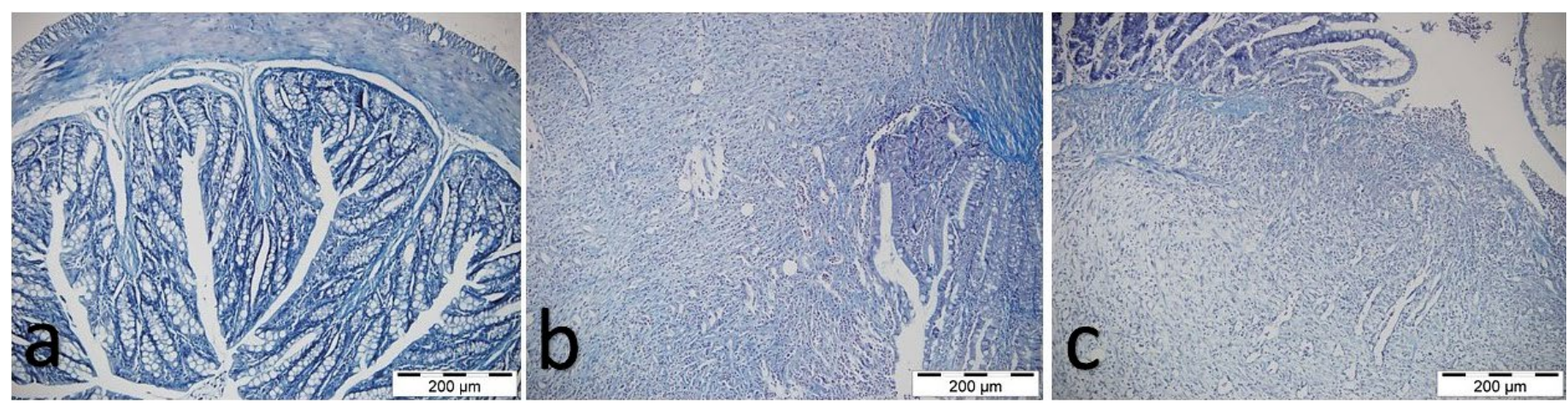

Fig. 4. Histopathological images of the cases (Masson's trichrome, Bar: $200 \mu \mathrm{m}$ ): a. control group, normal colon view; b. neovascularization + collagen synthesis in the anastomosis line (group III); c. formation of numerous new vessels in the anastomosis line, increased fibroblastic activity and collagen synthesis (group IV)

epithelium. In samples obtained from the other rats in the same group, there was a remarkable neutrophilic granulocyte infiltration in all layers that was more prominent on the mucosal surface, despite the presence of fibroblastic activity and neovascularisation in the anastomosis region. Irregular collagen distribution with neovascularisation on the anastomosis line was observed after staining with Masson's trichrome to evaluate collagen distribution in samples obtained at day 5 from the rats in group III (Fig. 4b).

There was a remarkable increase in fibroblastic activity, neovascularisation and wound healing at the fibrous repair stage in all samples obtained from group IV. The presence of mononuclear cells in the anastomosis region and sporadic PMNLs on the mucosal surface of the anastomosis line were observed. As in group III, epithelial regeneration on the mucosal surface was observed in this group, but did not completely close the anastomotic line. Samples prepared with Masson's trichrome stain showed new vessel formation on the anastomotic line together with increased fibroblastic activity and collagen synthesis (Fig. 4c).

As no histopathologic lesions were observed in the control group without anastomosis and the dexpanthenoladministered control group without anastomosis, these groups were not included for statistical analysis. Statistical analysis was performed for the test group with anastomosis and the dexpanthenoladministered test group with

Explanations: as in Tab. 3. anastomosis. Statistical analyses were not performed for parameters that showed the same scores in the rats of these two groups. Different scores were detected only for PMNL. In the Mann-Whitney U test, PMNL data were compared between the two groups $(p=0.024)$, and the total score $(p=0.025)$ was significantly different.

Biochemical findings. NO and MDA levels, as well as TAC and TOC at days 0-5 in serum and colon homogenates are shown in Tables 3 and 4, respectively.

There were no statistically significant differences in serum NO and MDA levels or in TAC and TOC in

Tab. 3. Distribution of serum NO ( $\mu \mathrm{mol} / \mathrm{L}$ g wet tissue), MDA ( $\mu \mathrm{mol} / \mathrm{L} \mathrm{g}$ wet tissue), TAC (mmol Trolox eq/L g wet tissue) and TOC ( $\mu$ mol $\mathrm{H}_{2} \mathrm{O}_{2} \mathrm{eq} / \mathrm{L} \mathrm{g}$ wet tissue) values in the groups on days 0 and 5 (mean value \pm standard error)

\begin{tabular}{|c|c|c|c|c|c|c|}
\hline \multicolumn{2}{|c|}{ Parameters and days } & \multirow{2}{*}{$\begin{array}{c}\text { Group I } \\
10.94 \pm 0.99\end{array}$} & \multirow{2}{*}{$\begin{array}{c}\text { Group II } \\
9.65 \pm 0.76\end{array}$} & \multirow{2}{*}{$\begin{array}{c}\text { Group III } \\
10.77 \pm 1.14\end{array}$} & \multirow{2}{*}{$\begin{array}{c}\text { Group IV } \\
10.77 \pm 0.27\end{array}$} & \multirow{2}{*}{$\begin{array}{c}p \text { value } \\
0.118\end{array}$} \\
\hline \multirow{3}{*}{ NO } & O.day & & & & & \\
\hline & 5.day & $10.77 \pm 0.67^{a}$ & $9.02 \pm 0.86^{a}$ & $24.10 \pm 2.05^{c}$ & $15.90 \pm 1.07^{b}$ & $<0.001$ \\
\hline & $\mathrm{p}$ value & 0.665 & 0.276 & $<0.001$ & 0.001 & - \\
\hline \multirow{3}{*}{ MDA } & O.day & $6.73 \pm 0.61$ & $6.19 \pm 0.64$ & $6.41 \pm 0.77$ & $6.93 \pm 0.63$ & 0.185 \\
\hline & 5.day & $7.98 \pm 1.18^{\mathrm{a}}$ & $5.50 \pm 0.71^{a}$ & $44.34 \pm 4.90^{\circ}$ & $17.70 \pm 1.19 \mathrm{~b}$ & $<0.001$ \\
\hline & $p$ value & 0.081 & 0.125 & $<0.001$ & $<0.001$ & - \\
\hline \multirow{3}{*}{ TAC } & 0.day & $1.16 \pm 0.17$ & $1.23 \pm 0.15$ & $1.29 \pm 0.15$ & $1.11 \pm 0.89$ & 0.109 \\
\hline & 5.day & $1.18 \pm 0.16^{\mathrm{ab}}$ & $1.44 \pm 0.16^{b}$ & $0.90 \pm 0.37^{a}$ & $1.09 \pm 0.11^{\mathrm{a}}$ & 0.002 \\
\hline & $p$ value & 0.809 & 0.020 & 0.028 & 0.755 & - \\
\hline \multirow{3}{*}{ TOC } & 0.day & $0.53 \pm 0.06$ & $0.53 \pm 0.03$ & $0.52 \pm 0.04$ & $0.59 \pm 0.08$ & 0.089 \\
\hline & 5.day & $0.52 \pm 0.12^{\mathrm{a}}$ & $0.54 \pm 0.08^{\mathrm{ab}}$ & $0.78 \pm 0.12^{c}$ & $0.68 \pm 0.05^{\mathrm{bc}}$ & $<0.001$ \\
\hline & p value & 0.874 & 0.769 & 0.001 & 0.108 & \\
\hline
\end{tabular}

Explanations: $a, b, c$ show statistical differences in the same line $(\mathrm{p}<0.05)$; $\mathrm{NO}$ - nitric oxide; MDA - malondialdehyde; TAC - total antioxidant capacity; TOC - total oxidant capacity

Tab. 4. Distribution of NO ( $\mu \mathrm{mol} / \mathrm{L}$ g wet tissue), MDA ( $\mu \mathrm{mol} / \mathrm{L}$ g wet tissue), TAC (mmol Trolox eq/L $\mathrm{g}$ wet tissue) and $\mathrm{TOC}\left(\mu \mathrm{mol} \mathrm{H}_{2} \mathrm{O}_{2} \mathrm{eq} / \mathrm{L} \mathrm{g}\right.$ wet tissue) values for intestinal tissue in the groups on day 5 (mean value \pm standard error)

\begin{tabular}{|l|c|c|c|c|c|}
\hline \multirow{2}{*}{ Parameters } & \multicolumn{4}{c|}{ Groups } & P value \\
\hline NO & I & II & III & IV & \\
\hline MDA & $6.89 \pm 0.30^{\mathrm{ab}}$ & $5.72 \pm 0.42^{\mathrm{a}}$ & $16.01 \pm 0.85^{\mathrm{c}}$ & $8.47 \pm 0.51^{\mathrm{b}}$ & $<0.001$ \\
TAC & $3.87 \pm 0.17^{\mathrm{b}}$ & $2.31 \pm 0.19^{\mathrm{a}}$ & $7.55 \pm 0.41^{\mathrm{c}}$ & $3.08 \pm 0.22^{\mathrm{ab}}$ & $<0.001$ \\
TOC & $1.88 \pm 0.03^{\mathrm{c}}$ & $1.61 \pm 0.09^{\mathrm{bc}}$ & $1.06 \pm 0.08^{\mathrm{ab}}$ & $1.33 \pm 0.12^{\mathrm{a}}$ & $<0.001$ \\
\hline
\end{tabular}


group I between day 0 and day $5(p>0.05)$. In group II, serum TAC on day 5 was statistically higher than that on day $0(p=0.22)$. In group III, serum NO and MDA levels and TOC on Day 5 were significantly higher than those on day $0(p \leq 0.001)$. Similarly, serum TAC in group III showed a significant decrease on day $5(p=0.028)$. In group IV, serum NO and MDA levels were significantly higher on day $5(\mathrm{p} \leq 0.001)$. Moreover, serum TAC decreased on day 5 , whereas serum TOC increased, but there was no statistically significant difference $(\mathrm{p}>0.05$, Tab. 3$)$.

NO and MDA levels and TOC in colon homogenates were significantly higher in group III than they were in the other groups $(p<0.001)$. TAC in colon homogenate was lower in groups III and IV than in group I, and this was statistically significant $(\mathrm{p} \leq 0.001$, Tab. 4$)$.

Various studies have reported on prevention of anastomotic leakage after colon surgery. For this purpose, different suturing techniques, synthetic and organic meshes, absorbable surgical barrier films, antibiotic prophylaxis, prebiotics and omentoplasty have been tested $(1,4,9,26)$. These studies have focused on surgical techniques rather than medical support. In the present study, the aim was to seal the anastomotic line by accelerating the healing process through the intraperitoneal use of dexpanthenol, which plays an active role in wound healing, without the need for a surgical operation following colon anastomosis.

It has been reported that dexpanthenol could be used topically, orally or by injection $(18,19,21,24)$. At the same time, it was reported that local applications of dexpanthenol, which is the alcohol form of pantothenic acid (Vitamin B5), increases mitosis and accelerates wound healing. ${ }^{1}$ It has been reported that adhesions can develop at the operation site as a result of various application mistakes, such as the overuse of cautery at the intraoperative stage, haemostatic forceps being clamped for a long time and too tight or suture mistakes, and it is suggested that adhesion mostly occurs due to anastomotic leakage in the postoperative period $(9,12)$. In a study comparing the intravenous (IV) and intraperitoneal (IP) use of dexpanthenol, Akdeniz et al. report that the IP use is more effective in preventing adhesion formation compared to the IV use (1). In the present study, the purpose was to determine the effectiveness of intraperitoneally administered dexpanthenol in preventing adhesion formation by accelerating wound healing. On the $5^{\text {th }}$ day of evaluation of all rats in all groups, the peritoneum was examined macroscopically, and adhesions were detected in 6 cases in group III and 4 cases in group IV. In a histopathologic comparison of groups III and IV using the Mann-Whitney U test, PMNL $(p=0.024)$ and total scores $(p=0.025)$ were significantly different between the two groups, and this was interpreted as a proof of dexpanthenol being effective in preventing adhesion formation. Moreover, histopathology evaluation revealed that fibroblastic activity, angiogenesis and neovascularisation in the group with anastomosis (group III) were less developed compared to those in the dexpanthenol-administered group with anastomosis (group IV). Therefore, our hypothesis is that the acceleration of healing favours impermeability in the anastomosis line and thus prevents adhesions. We believe that the difference between the intestine bursting pressures in favour of group IV cannot be explained by any mechanism other than dexpanthenol increasing regeneration. In view of these three findings, which confirm each other, our results appear to be parallel to the results reported by Akdeniz et al with regard to dexpanthenol administered IP decreasing anastomosis leakage by accelerating regeneration in the anastomosis line.

Atony is one of important complications encountered after enterotomy-enterectomy procedures. Since it is known that pantothenic acid plays a role in the synthesis of acetylcholine, which is a neurotransmitter (1), it has been reported that dexpanthenol has been used in the treatment of intestinal atony to benefit from this effect $(4,18)$. Minimal movement of wound lips is desirable in wound healing, as it is known to accelerate healing (7). According to the macroscopic and histopathologic results from our study, dexpanthenol accelerates healing compared to healing in the other groups. Regulation of intestinal motility is believed not only to contribute to wound healing, but also to prevent adhesion formation. Given the clinical, macroscopic and histopathologic findings, as well as intestine bursting pressure values, obtained in the short, 5-day post-operation period, the fact that regeneration was faster especially in group IV may be regarded as a proof of wound healing. Normally, it would appear that an increase in intestinal motility should have an effect of increasing anastomosis leakage. However, this paradoxical condition can be explained by low intestinal content and the acceleration of regeneration in the serosa through the effect of dexpanthenol.

In the evaluation of intestinal bursting pressures, it was seen that there was an increase in group II compared to group I, and in group IV compared to group III. These results show that dexpanthenol both increases resistance by accelerating healing in the anastomosis line and supports the endurance of healthy liver tissue. These results can be interpreted to mean that increased resistance due to accelerated regeneration in the anastomosis line and increase in the bursting pressure in the dexpanthenol-administered group that did not undergo operation were caused by the known healing and antioxidant effects of dexpanthenol.

Dexpanthenol is converted into pantothenic acid when administered orally or parentally. It has been reported that dexpanthenol, which has antioxidant properties, shows epithelising effects and plays a positive role in wound healing (18). In a histopathologic comparison between groups III and IV, all samples from group IV showed a remarkable increase in 
fibroblastic activity and predominance of angiogenesis and wound healing at the proliferative fibrous repair stage. Formation of a large number of new vessels on the anastomosis line and a remarkable increase in fibroblastic activity in group IV compared to that in group III, as well as collagen synthesis and faster regeneration in mucosal epithelium, suggest an epithelising effect of dexpanthenol.

With regard to biochemical parameters examined in the present study, NO and MDA levels were significantly increased in group III. It was seen that in group IV, where dexpanthenol was administered in addition to anastomosis, this increase was less pronounced compared to that in group III. This smaller increase in NO and MDA levels in group IV compared to group III is thought to have been caused by the antioxidant effect of dexpanthenol. It has been reported that oxidative stress parameters such as NO and MDA increase in inflammatory conditions $(1,2,13,18,22)$. It was detected that NO, MDA and TOC levels increased significantly in group III at day 5 compared to the levels at day $0(\mathrm{p} \leq 0.001)$, and TAC decreased at a statistically significant level $(p=0.028)$. In the dexpanthenoladministered group IV, there was an increase in these stress parameters at day 0 which was much smaller compared to group III, and this result is again due to the effects of dexpanthenol. While colon homogenate NO, MDA, and TOC levels in group III increased significantly parallel to the serum concentrations in the same group, colon homogenate NO and MDA values in group IV being similar to those in group I were thought to reflect antioxidant effects of dexpanthenol in the inflamed tissues.

In conclusion, the findings of this study, which aimed to clinically, histopathologically and biochemically evaluate the effects of dexpanthenol administered intraperitoneally to rats with colon anastomosis on healing, suggest that dexpanthenol decreases oxidative stress in colon tissue and serum during the postoperative process through its antioxidant properties and prevents adhesion formation by promoting anastomotic sealing due to its positive effect on healing. It can therefore be inferred that postoperative local or diffuse peritonitis can be prevented by avoiding anastomotic leakage following all stomach-intestinal procedures, and related adhesions can be decreased. Hence, it is believed that IP dexpanthenol has the potential to be introduced into veterinary practice by being tested in clinical cases as well.

\section{References}

1. Akdeniz Y., Tarhan Ö. R., Barut $\dot{I}$ : Can dexpanthenol prevent peritoneal adhesion formation? An experimental study. Turk. J. Trauma Emerg. Surg. 2007, 13, 94-100.

2. Aktas M. S., Kandemir F. M., Kirbas A., Hanedan B., Aydin M. A.: Evaluation of oxidative stress in sheep infected with Psoroptes ovis using total antioxidant capacity, total oxidant status, and malondialdehyde level. J. Vet. Res. 2017, 61, 197-201.

3.Buchmiller-Crair T. L., Kim C. S., Won N. H., Chopourian H. L., Shaw K. S., Fonkalsrud E. W.: Effect of Acute Anemia on the Healing of Intestinal
Anastomoses in the Rabbit. J. Trauma Injury Infect. Crit. Care 2001, 51, 363-368.

4. Dinçel O.: Polypropilene mesh covered colonic anastomosis. Results of a new anastomosis technique. T. C. Ministry of Health Istanbul Training and Research Hospital Third General Surgery Clinic. Master Thesis 2007.

5. Erel O.: A novel automated direct measurement method for total antioxidant capacity using a new generation, more stable ABTS radical cation. Clin. Biochem. 2004, 37, 277-285.

6. Erel $O .:$ New automated colorimetric method for measuring total oxidant status. Clin. Biochem. 2005, 38, 1103-1111.

7.Ermutlu C. S., Kllıc E., Aksoy O., Yayla S., Baran V., Dag S., Ulkay M. B., Aydın U., Demirtas B.: Effect of Bovine Corpus Vitreum on Full-thickness Dermal Wound Healing: An Experimental Study in Rats. Kafkas Univ. Vet. Fak. Derg. 2018, 24, 33-38.

8. Fakioglu D.: Effect of resorbable surgical barrier film use in anastomos security in colon anastomosis. T.C. Ministry of Health Dr. Lütfi Kirdar Training and Research Hospital Second General Surgery Clinic. Master Thesis 2008.

9. Gunerhan Y., Sulu B., Oztürk B., Vural S. A., Ermutlu C. S., Aksoy A., BüyükF. The effect of kefir on the healing of colonic anastomosis in rabbits. Kafkas Üniv. Vet. Fak. Derg. 2009, 15, 119-124.

10. Hasanoglu A., Erkan S., Temel S., Urhan M. K., Güler O.: Effect of Sildenafil Citrate on healing of colonic anastomoses. Turk. Med. J. 2007, 1, 66-75.

11. Jenkins S. D., Klamer T. W., Parteka J. J., Condon R. E.: A comparison of prostetic materials used to repair abdominal wall defects. Surgery 1983, 94, 392-398

12. Koksal N., Uzun M. A., Özkan Ö. F., Kayahan M., Ipcioglu O. M., Günerhan Y., Ergün E., Güneş P.: Effects of hemoperitoneum on wound healing and fibrinolytic activity in colonic anastomosis. Turk. J. Trauma Emerg. Surg. 2012, 18, 283-288.

13. Lykkesfeldt J., Svendsen O.: Oxidant and antioxidants in disease: Oxidative stress in farm animals. Vet. J. 2007, 173, 502-511.

14. Mall J. W., Schwenk W., Philipp A. W., Büttemeyer R., Pollmann C.: Intraperitoneal Administration of the Angiogenesis Inhibitor Thalidomide Does Not Impair Anastomotic Healing following Large Bowel Resection in a Rabbit Model. World J. Surg. 2003, 27, 1119-1123.

15. McCue J. L., Philips R. K. S.: Sutureless intestinal anastomoses. Br. J. Surg. 1991, 78, 1291-1296.

16. Merad F., Hay J. M., Fingerhut A., Flamant Y., Molkhou J. M., Laborde Y. Omentoplasty in the prevention of anastomotic leakage after colonic or rectal resection: a prospective randomized study in 712 patients. Annals Surgery 1998, 227, 179-186.

17. Miranda K. M., Espey M. G., Wink D. A.: A rapid, simple spectrophotometric method for simultaneous detection of nitrate and nitrite. Nitric Oxide 2001 , 5, 62-71. DOI: 10.1006/niox.2000.0319

18. Ozkısacık S., Yazıcı M., Gürsoy H., Serter M., Culhacı N.: Does dexpantenol protect the kidney from ischemia-reperfusion injury? Turk. Neph. Dial. Transpl. 2011, 20, 146-149.

19. Slyshenkov V. S., Dymkowska D., Wojtczak L.: Pantothenic acid and pantotheno increase biosynthesis of glutathione by boosting cell energetics. FEBS Lett. 2004, 569, 169-172.

20. Slyshenkov V. S., Piwocka K., Sikora E., Wojtczak L.: Pantothenic acid protects jurkat cells against ultraviolet light-induced apoptosis. Free Radic. Biol. Med. 2001, 30, 1303-1310.

21. Slyshenkov V. S., Rakowska M., MoiseenokA. G., Wojtczak L.: Pantothenic acid and its derivatives protect Ehrlich ascites tumor cells against lipid peroxidation. Free Radic. Biol. Med. 1995, 19, 767-772.

22. Tkachenko H., Grudniewska J., Pękala A., Terech-Majewska E.: Oxidative stress and antioxidant defence markers in muscle tissue of rainbow trout (Oncorhynchus mykiss) after vaccination against Yersinia ruckeri. J. Vet. Res. 2016, 60, 25-33.

23. Verhofstad M. H. J., Lange W. P., Van Der Laak J. A. W. M, Verhofstad A. A. J., Hendriks T: Microscopic analysis of anastomotic healing in the intestine of normal and diabetic rats. Dis. Colon Rectum 2001, 44, 423-431.

24. Wojtczak L., Slyshenkov V. S.: Protection by pantothenic acid against apoptosis and cell damage by oxygen free radicals - the role of glutathione. Biofactors 2003, 17, 61-73

25. Yoshioka T., Kawada K., Shimada T., Mori M.: Lipid peroxidation in maternal and cord blood and protective mechanism against activated-oxygen toxicity in the blood. Am. J. Obstet. Gynecol. 1979, 135, 372-376.

26. Young H. L., Wheeler M. H.: Collagenase inhibition in the healing colon J. Royal Soc. Medicine 1983, 76, 32-36.

Corresponding author: Ass. Prof. Dr. Celal Sahin Ermutlu, Kafkas University, Faculty of Veterinary Medicine, Department of Surgery, Kars, Turkey, TR 36100; e-mail: sahinermutlu@hotmail.com 